\title{
HISTOLOGY AND FUNCTION OF THE VENOM GLAND SYSTEM IN FORMICINE ANTS ${ }^{1}$
}

\author{
By Henry R. Hermann, Ron Baer ${ }^{2}$ and Margaret Barlin ${ }^{3}$ \\ Department of Entomology \\ University of Georgia \\ Athens, Georgia 30602
}

The hymenopterous venom apparatus characteristically is associated with two sac-like structures, one of which is responsible for venom production and storage. The venom components generally include one or more filaments, a gland-like area and venom reservoir. According to Blum and Hermann (1969), the filaments in some hymenopterous insects apparently function in part in the pick-up of venom precursors and the transference of these compounds to the adjacent convoluted gland. Venom synthesized in the convoluted gland moves to the venom sac where it is stored until it is used.

In a brief investigation of these venom components in formicine ants, we realized that the general picture reported by Blum and Hermann ( 1969) varied slightly in different aculeates. The venom components in formicines are uniquely arranged and facilitate a detailed study of the cells throughout the structures that are responsible for venom production and storage.

\section{METHODS}

The venom components of several formicine species were examined carefully and found to be identical in structure. Camponotus pennsylvanicus was chosen to represent the group.

The convoluted gland was unraveled by pulling the entire gland from the sac and pulling on the proximalmost end of the tube on the basal side of the gland. In this way the length of the tube composing the convoluted gland, the point of junction between gland and sac and the point of junction between gland and filaments were determined.

\footnotetext{
${ }^{1}$ This research was supported by a grant from the National Science Foundation (GB-38482)

2Present address: Department of Entomology, Virginia Polytechnic Institute and State University, Blacksburg, Virginia 24601.

3Present address: Department of Entomology, Texas A \& M University, College Station, Texas.
}

Manuscript received by the editor March 4, 1975 
Venom components were embedded in toto, sectioned at $7 \mu$ and stained with Delafields hematoxylin and eosin y and Mallory's triple stain. Longitudinal sections were valuable in examining the cellular differences between the venom components.

MTT (3-(4,5-dimethyl-thiazolyl-2)-2,5-diphenyl tetrazolium bromide, a tetrazolium salt with a high redox potential, was employed as an easily reduced electron acceptor, as outlined by Blum and Hermann (1969). This colorless compound is converted to a purplishblack formazan when reduced. Since the formazan formed by MTT chelates with certain metals to form non-crystalline deposits, cobalt ions were added to the reaction mixture, resulting in the formation of a metallic cobalt-formazan complex.

\section{Results and Discussion}

Venom is forced from the large reservoir through an acidpore (Acpr, Fig. I A) in formicine ants. A sting is wanting (Hermann and Blum, 1968). Most of the sac is entirely surrounded by relatively sparse circular muscle, which assists in the evacuation of venom. Abundant muscles surrounding the base of the sac are chiefly responsible for the rapid movement of venom out of the sac (Mus, Fig. 2 A).

The venom reservoir (PS, Fig. I B) is large, covered by a simple squamous epithelium ( $R W$ ) and lined internally by a well defined intima. There are no cells incorporated in the reservoir that have a glandular function.

The convoluted gland is an extremely long tube, averaging $376 \mathrm{~cm}$ ( 15 in.) in length. It attaches to the venom reservoir near the latter structure's apex (\# I, Fig. I, C; Jnct, Fig. I C) and is tightly coiled outward so that the filaments appear to extend from the base of the gland.

Two filaments branch from the single tube (\#2, Fig. I C) and meander through fatty tissue in the hemocoel. Upon a general examination of the reservoir it appears that the filaments extend from the base of the venom reservoir (Fig. I, B). The junction between convoluted gland and venom reservoir is hidden beneath the convoluted gland. After dissection the branches of the filaments come together at the base of the convoluted gland (\#2, Fig. I, C) but the basal region of the duct that forms the convoluted gland attaches to the reservoir near the latter structure's apex (\# I, Fig. I, C).

Cellularly, the filaments are very well developed glands themselves (FF, Fig. $2 \mathrm{C}$ ), the cells being large and supporting large nuclei. 

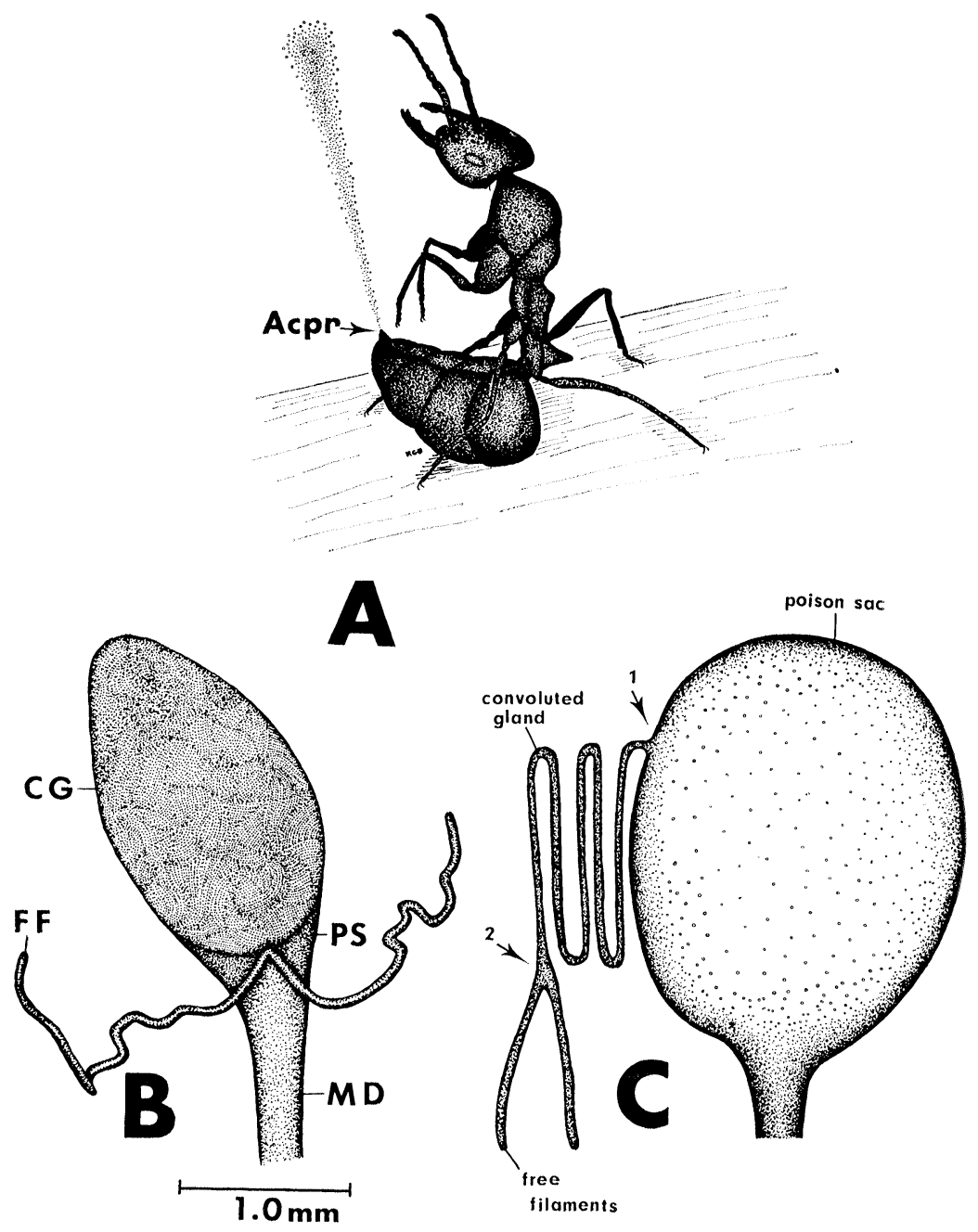

Fig. 1-A. Defensive attitude of formicine ants when venom is evacuated through the acidopore. B-Venom sac, showing its component parts in formicine ants. C-Diagrammatic drawing of the venom components and how they attach to one another in formicine ants. Acpr, Acidopore. CG, Convoluted gland. FF, free filamentous glands. PS, Poison sac (venom reservoir. 1, Junction between convoluted gland and venom reservoir. 2, Junction between single and branching ducts of filamentous gland. 
Each filament is made up of two or three cells in transverse section. The lumen in the filaments is well defined $(\mathrm{Lu})$. Since the filaments do possess well defined gland cells that probably have an important part in venom synthesis, it is appropriate to call them filamentous glands rather than free filaments as has been done in the past.

Originally, these filaments were called acid glands because it was believed that they produce an acid venom. This may be the case in the Formicinae but hymenopterons in other subfamilies of the Formicidae and in other aculeate families generally produce a basic venom. These filaments clearly are glandular in function, and they react significantly with tetrazolium salts in tests for enzymatic activity. Blum and Hermann (1969) reported faint reactions in the filaments of Pogronomyrmex badius (Latreille) with malate and $\alpha$-glycerophosphate. Although formazan deposition was apparent only in the distal part of the filaments in that investigation it is now believed that reactions to produce formazan probably occurred throughout the filaments but were difficult to see in the thinner basal region.

It is in the filaments or possibly in the associated fatty tissue that the beginnings of venom production probably occur. Fatty tissue in insects is a general center for intermediary metabolism. The citric acid cycle operates in the fat body. It can incorporate a wide variety of precursors into fat, protein and glycogen, and it functions much like a vertebrate liver in transmitting amino acids and making them available for anabolic processes in other tissues, in this case the filamentous glands and distal convoluted gland. An involvement with amino acids, which subsequently are built into venom proteins, takes place in non-formicine hymenopterons while other compounds would be utilized in formicines in the production of formic acid.

At the point of junction between the filaments and convoluted gland (\# I, Fig. I C; Jnct, Fig. 2 C) the cellular composition of the convoluted gland is similar to that of the filaments. However, cell type changes shortly beyond the attachment so that the convoluted gland is composed of polygonal cells with smaller nuclei and more internuclear cytoplasm (Fig. 2D). This cellular change indicates that the filaments are quite active as glands themselves and that much of the chemical change of venom precursors already has occurred before they reach the convoluted gland. The cellular composition remains much the same throughout the apical half of the convoluted gland. We have called this the cortex (Cor, Fig. 2 E) since there appears to be considerable glandular activity and hence continued production of venom components. 

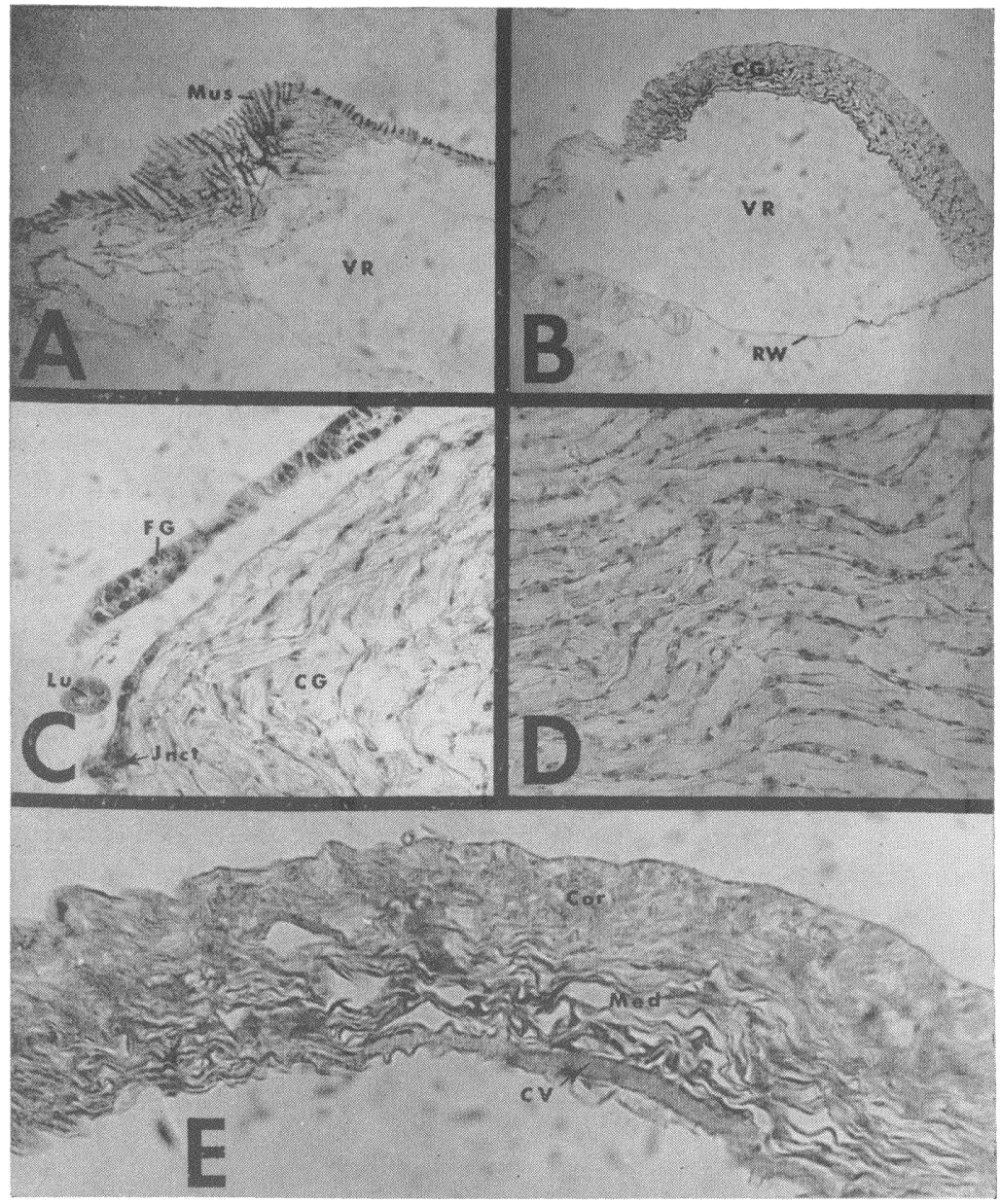

Fig. 2. Sections through the venom components of Camponotus pennsylvanicus. A - Oblique section, showing periodic transverse muscle in the basal region of the venom sac. B - Transverse section, showing the reservoir and convoluted gland. C-Horizontal section, showing flament and point of attachment on the convoluted gland. D-Horizontal section through the convoluted gland, showing the arrangement of polygonal cells along collection ducts. E-Transverse section through convoluted gland, showing a well-defined cortex and medulla. The large ducts adjacent to the venom reservoir are filled with venom. CG, Convoluted gland. Cor, Cortex of convoluted gland. CV, Collected venom. FG, Filamentous gland. Jnct, Junction between filamentous gland and convoluted gland. Lu, Lumen of filamentous gland. Med, Medulla of convoluted gland. Mus, Muscles transversely arranged around venom sac base. RW, Reservoir wall. VR, Venom reservoir. 
The basal half of the convoluted gland is chiefly composed of ducts lined with squamous cells and a strongly refringent intima (Med, Fig. $2 \mathrm{E}$ ). We have termed this region the medulla since it clearly functions in the collection of venom synthesized in the filaments and distal convoluted gland. The strongly developed intima probably is necessary for the protection of the remaining cellular components that link the convoluted gland with the reservoir. Formic acid is the chief constituent of formicine venom. The basal ducts in the medulla have an increasingly large lumen. Adnate to the venom sac a large supply of venom collects to flow into the reservoir. There appears to be no control of the venom flow from the medulla duct to the reservoir. No valves, dilator or occlusor muscles could be found.

Based on an examination of the venom components in most of the other formicid subfamilies, it appears that the venom components of hymenopterous insects other than the Formicinae have a similar composition cellularly, regardless of the arrangement between the glandular and reservoir regions. The convoluted gland in non-formicine hymenopterans is inside the reservoir. However, the basic connections between reservoir, convoluted gland and filamentous glands are similar; the venom components of all hymenopterans have been modified from a simple invagination of the integument.

Since fatty tissue functions in the storage of a diverse array of compounds and it is the site for intermediary metabolism, it is reasonable to assume that venom synthesis begins at this point. The filamentous glands, being closely associated with the fat, pick up venom precursors and change them considerably before they get to the convoluted gland. Venom synthesis is completed in the distal region of the convoluted gland, the proximal portion functioning only in the collection of venom and the transportation of it to the venom reservoir.

\section{SUMMARY}

The cells of the filaments, convoluted gland and venom reservoir vary considerably. The filaments are more glandular in function than previously expected. The convoluted gland clearly is part glandular (cortex) and part collecting duct (medulla). The movement of venom from the medullar region of the convoluted gland is unaided by a special release mechanism. In its release from the venom reservoir, venom is forced out through the acidopore by circular muscles most abundantly found near the base of the reservoir. 


\section{Literature Cited}

Blum, M. S. and H. R. Hermann.

1969. The hymenopterous poison gland: Probable functions of the main glandular elements. J. Georgia Entomol. Soc. 4:23-28.

Hermann, H. R. ANd M. S. Blum.

1968. The hymenopterous poison apparatus. VI. Camponotus pennsylvanicus (Hymenoptera: Formicidae). Psyche 75:216-227. 

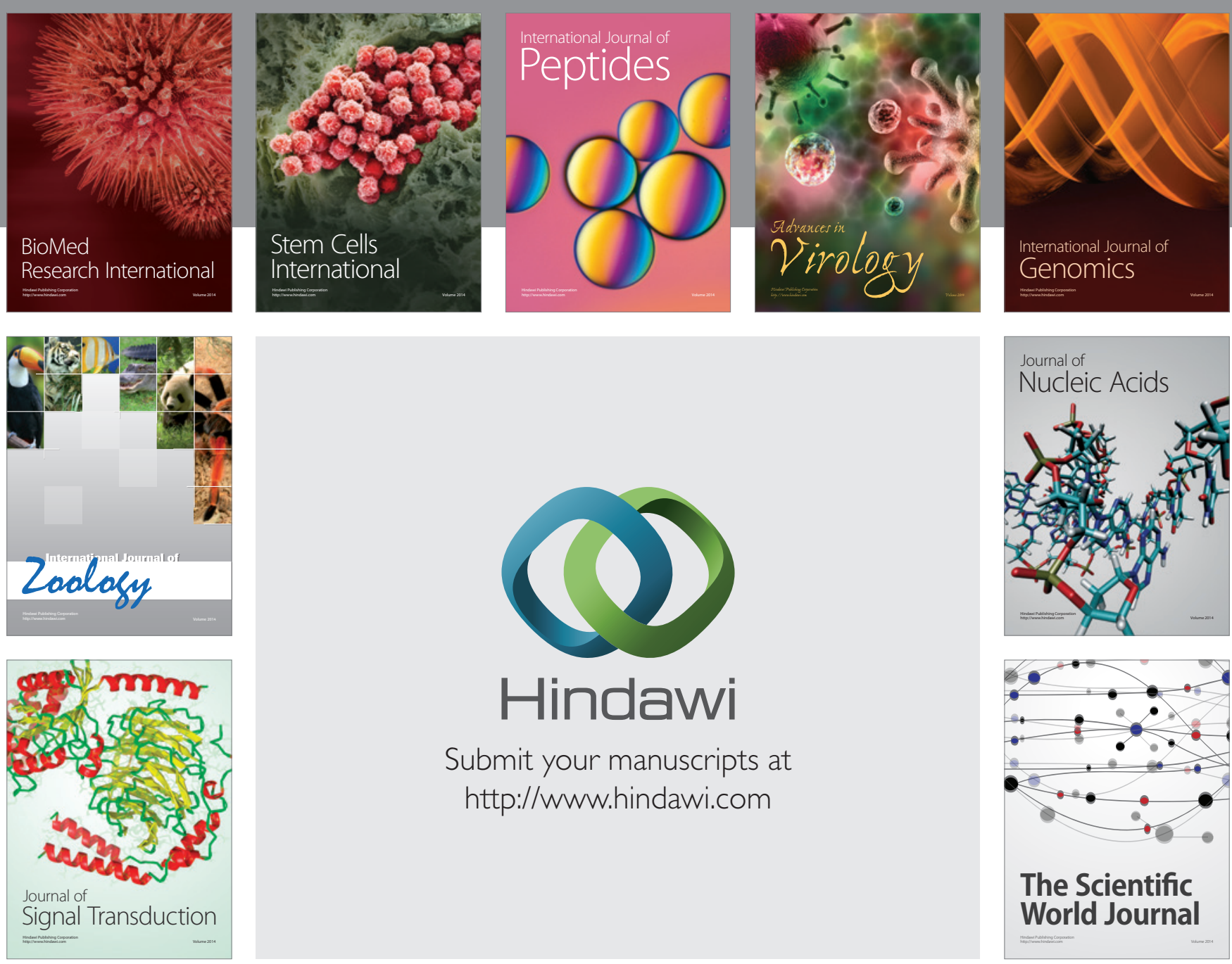

Submit your manuscripts at

http://www.hindawi.com
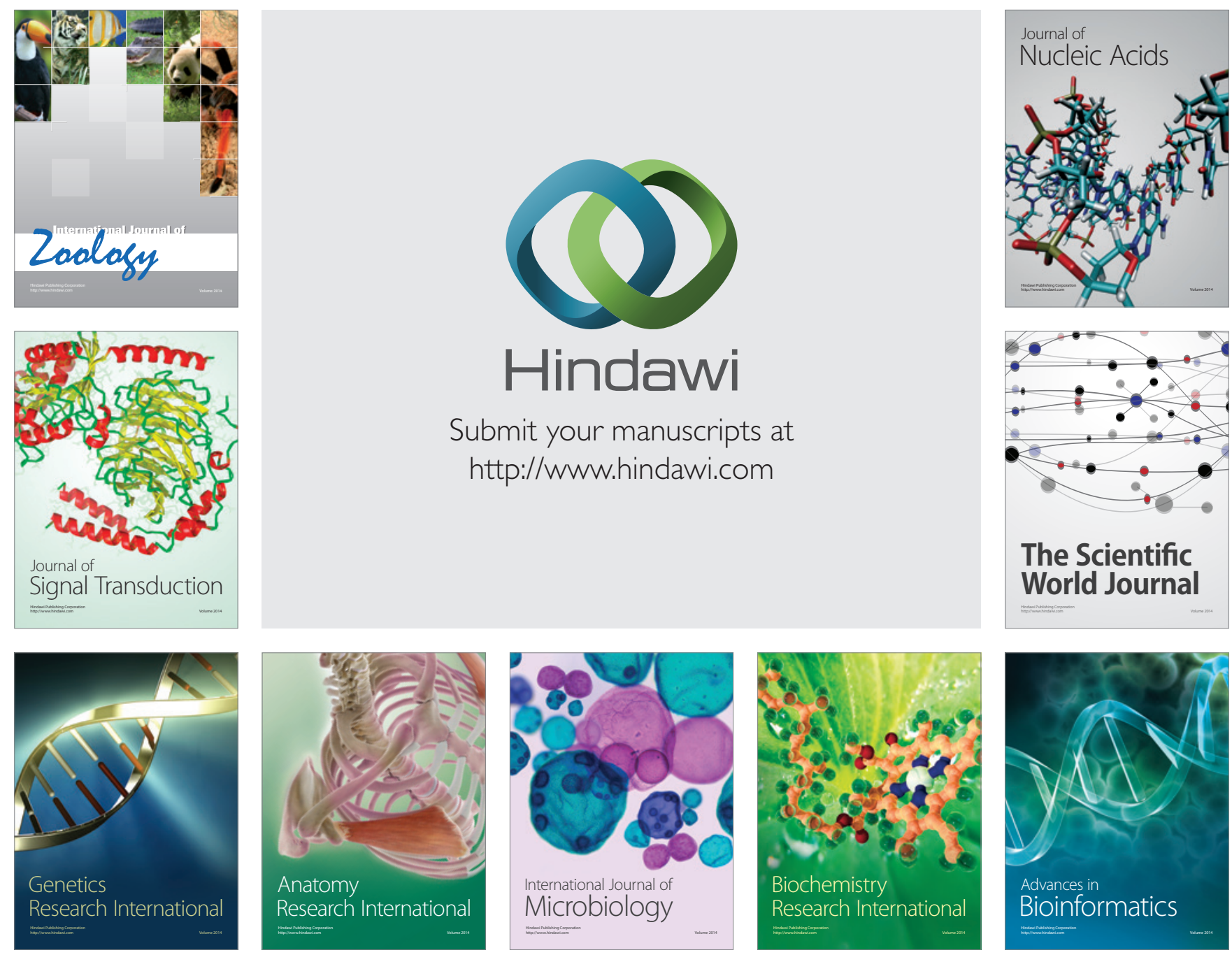

The Scientific World Journal
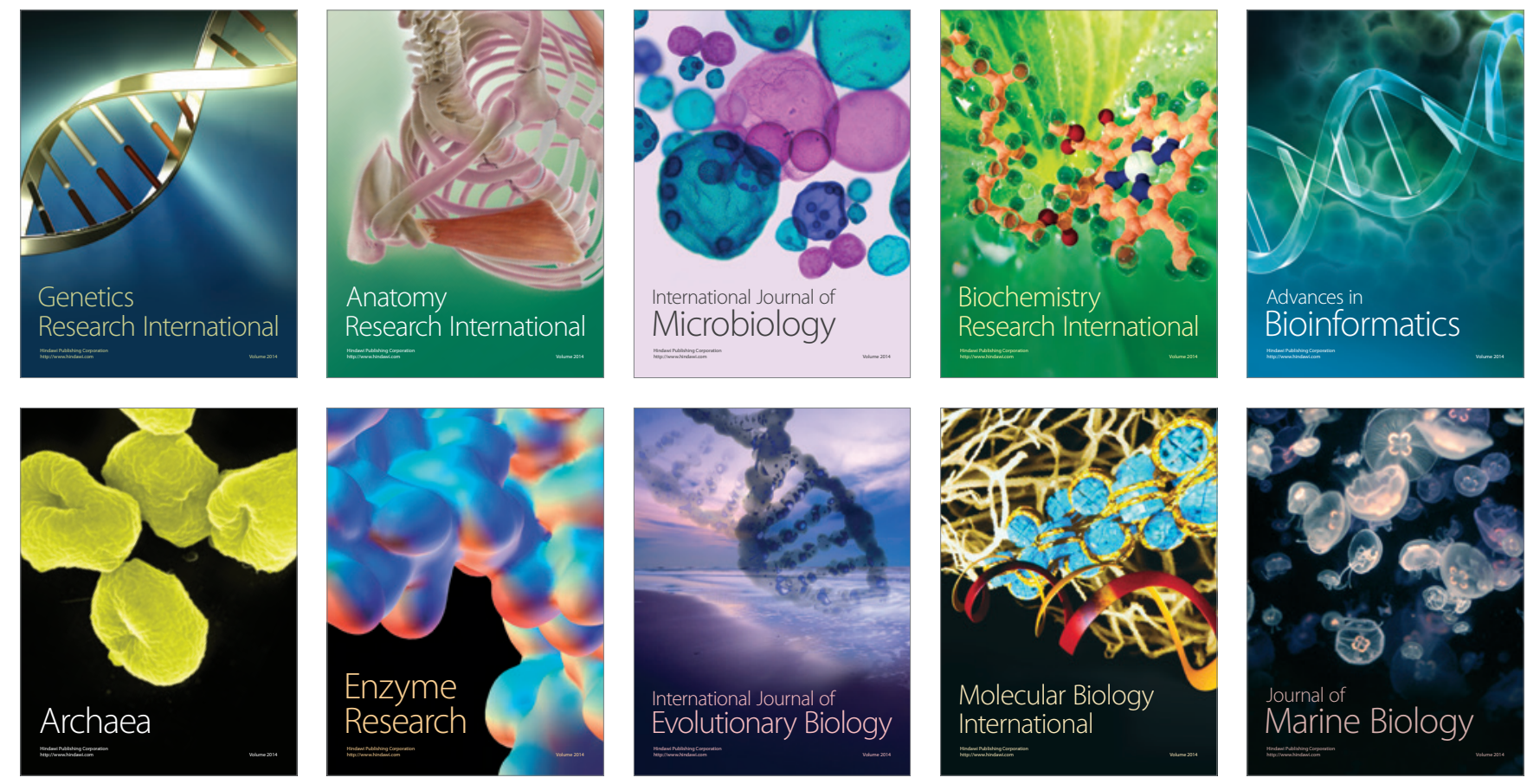